\title{
Toward an Interdisciplinary Learning Approach to Foster Students' Outlook of Universally Connected World: Starting from Music and Beyond
}

\author{
Feiqun Shu*, Panya Roongruang \\ Faculty of Music, Bangkok Thonburi University, Bangkok, Thailand \\ Email address: \\ shufeiqun1022@sina.com (Feiqun Shu), panyaroongruang@gmail.com (P. Roongruang) \\ ${ }^{*}$ Corresponding author
}

To cite this article:

Feiqun Shu, Panya Roongruang. Toward an Interdisciplinary Learning Approach to Foster Students' Outlook of Universally Connected World: Starting from Music and Beyond. International Journal of Education, Culture and Society. Vol. 6, No. 5, 2021, pp. 190-197.

doi: $10.11648 / j$. .jecs.20210605.14

Received: September 15, 2021; Accepted: October 4, 2021; Published: October 12, 2021

\begin{abstract}
Music never exists for its own sake. On the contrary, it connects to the universe including Nature, society, and human beings. Music originated from people's labor and life and has always reflected human conditions related to temporal and spatial elements. It is our belief that music can function as an educatively meaningful window through which the students explore the world with wider views and deeper thoughts. Based on these beliefs, we postulate an interdisciplinary approach starting from music and beyond it to foster students' outlook of universally connected world. A conceptual model is conceived by the authors which describes the students' hierarchical progress possibly gained from purposefully designed learning in an interdisciplinary manner. To further rationalize the feasibility for such a learning approach, we propose a down-to-earth way of thinking that music relates to language in lyrics of songs, bears geo-historical footprints because it originates temporally and spatially. From these clues, a common attribute can be found to thread the whole learning process involving several subjects integrated as a whole, rather than the school subjects learned separately. Given an exemplary project for the students to explore two types of folk songs in the North and the South of China, they are led to find a common attribute focusing on isomorphic direction of move between dialect tones of lyrics and tunes of folk songs, discover the inner connections hidden beneath the surface of present phenomena, and dwell on the significant insights which enable them to act like a thinker. The interdisciplinary learning illustrated as a case project here purports to prompt our colleagues that the educative values of music are far from fully recognized and these values should function to a full degree for the young generation to emancipate the constraints of thinking and develop creative minds.
\end{abstract}

Keywords: World Outlook, Interdisciplinary Learning, Music Connects, Common Attribute

\section{Introduction}

\subsection{The Significance of Interdisciplinary Learning}

Historically, the purpose to motivate students to learn across different aspects of the world can be found early in the educational philosophy of Confucius. In chapter seven of The Analects of Confucius, he encouraged students to link to other things from one aspect previously learned or being learned presently. Confucius said, literally translated from ancient Chinese to modern English, that "when I have pointed out one corner of a square to anyone and he does not come back with the other three, I will not point it out to him a second time [1]."
The implication here is to expect the learner to dwell on the target of learning to a deeper and wider level, not just to memorize the immediate facts with a naïve knowing.

Contemporarily, it has been one hundred years since interdisciplinary approaches were proposed in U.S. schools that dated "at least to the reforms of progressive educators during the 1920s and 1930s, when advocacy for new organizations of subject matter were linked with proposals for a more student-centered, progressive pedagogy...... Interdisciplinary approaches, supporters claim, have the potential to increase student engagement, raise achievement [2]." Similar trends emerging at the turn of the 19th and 20th centuries were reported in Bruner's landmark monograph The 
Process of Education. He pointed out that "the study of 'transfer' provides the type case - the problem of the gain in mastery of other activities that one achieves from having mastered a particular learning task [3]."

According to our observation in recent years, interdisciplinary learning, like what was advocated by early progressive educators and others, may well be hoped to foster students' competencies such as understanding and usable abilities rather than mere mastery of knowledge and skill in a specific discipline or subject. The outcomes of such learning, in the sense of cognitive operations, are hierarchical, from early awareness of different objects or concepts possessing something in common or similarity, to intermediate level of applying certain strategies for purposeful transfer across different fields and pondering on further possibilities in solving problems. Gradually, a philosophically minded level is approached that enables the learner to look at the world from a universally connected perspective. It is at such a high level that we are striving to achieve.

The significance of interdisciplinary learning can be further demonstrated in the case of Auenbrugger (1722-1809) who invented percussion that saved millions of lives, a landmark contribution widely known in medical community. He was inspired by an experience in childhood when his father taught him to tap on oak barrels in the family wine cellar to judge whether there was wine by listening to the sound effect: empty or full. Here was a professional medical technique invented and there had been a routine experience few people would glance at it with further thoughts. The two phenomena seemed irrelevant with each other while a thoughtful mind, however, noticed a common principle hidden between them. A giant progress was thus made for human health from this outlook of the world. The significance of learning in the way of Auenbrugger catches the essence of the world including mental working of human beings, that is, the world is universally connected as a whole and the right way to view the world should be in accordance with this truth. As far as education concerned, interdisciplinary learning should be given serious attention for fostering students' mental growth with broader and deeper views to meet today's challenges calling for great minds which are not possibly produced by discipline-isolated and test-oriented schooling.

A critical point can be concluded that a creative mind can never come out from learning of isolated disciplines or what we call school subjects studied in a separate way. To explain the distinct boundary between the two types of learning, we would like to share an interesting observation related to traditional Chinese medicine. It has been thousands of years for traditional Chinese medicine to develop a philosophy with which a thoughtful traditional Chinese doctor never treats illness with an isolated way to think of the patient's condition. It would be silly to treat the case of headache without considering other causes beyond the patient's head. Based on a holistic outlook of the world, traditional Chinese medicine considers the case from comprehensively related perspectives. It is the key to understand the difference between traditional Chinese medicine and modern ones which are based on scientific and technological paradigm. Ironically, when one enters a Chinese herbal medicine shop, he sees a different scene where all sorts of the herbs are separately kept in many small delicate drawers. The traditional Chinese medicine insists on a holistic way to treat the illness to synthesize the prescribed herbs with related complicacy, just like what has been sought after by interdisciplinary pioneers to let students see and think of the world in related ways, always linking one thing to the many, whereas the way to store the medical herbs separately placed in isolated containers - is in no way like the core philosophy of Chinese medicine. This analogy illustrates school disciplines or subjects to be learned by students in distinctly different ways. It is correct that school subjects or disciplines are there to be learned, nothing wrong. However, the ways to learn them are quite different. Different ways of learning result in the different minds. We advocate the interdisciplinary learning because it results in the minds connecting the world and recreating a new world, not for reciting the messages from textbooks to test papers.

\subsection{A Proposed Hierarchical Model}

A conceptual model is tentatively conceived by the authors of this article and presented in table 1. These hierarchical descriptions, from bottom to the top, do not mean a stepwise pace to follow strictly. Rather, it means a conceptual principle outlined for students' mental work, which is also with an emphasis on students' inner excitements such as emotional responses, self-motivations, as well as curiosity and fancy, etc. that play crucial roles in metal functioning.

Table 1. A Proposed Model of Students' Mind Performance through Interdisciplinary Learning.

\begin{tabular}{ll}
\hline Level & Hierarchical Performance \\
\hline High & $\begin{array}{l}\text { A universally connected world view has been established through varieties of leaning situations and demonstrated in the ability to solve } \\
\text { problems from multidimensional perspectives with novelty and flexibility. }\end{array}$ \\
Be able to experiment with self-discovered transferable insights and strategies in more situations to test the strategies and expand the \\
Intermediate \\
successful accomplishments.
\end{tabular}

This model might be applied to arts and humanities, philosophy, and social sciences, as well as natural sciences for the purpose to lead and assist students developing their mind work through an interdisciplinary way of learning. An example will be presented later for an interdisciplinary learning approach to start from music and connect to other disciplines beyond music. Before the example is illustrated, it is necessary to meditate on something fundamental as a rationale for such an approach. 


\section{A Rationale: Starting from Music and Beyond}

\subsection{Existing Views to Support the Rationale}

To Pythagorean philosophers in ancient Greece, music was viewed as a microcosm "governed by mathematical laws that operated both in the visible and invisible organization of the universe [4]." A similar belief from a more profound perspective was expressed later by Chinese in "The Book of Rites" that "Grand Music is harmonious with the Universe - the Heaven and the Earth." These ideas of music in connection with the Nature are elaborated further recently by Dr. Elliott at New York University who criticizes the view of music as sounds alone and postulates that music must be considered in cultural, historical, and social contexts with moral concerns such as the flourishing of people and communities on humanist good [5-7]. To explain the significance beneath the surface of music, Elliott further cites from economic and political perspectives by French scholar Jacques Attali: "Music is more than an object of study: it is a way of perceiving the world [8]."

All these points of view, to cite but a few, lead to a conclusion that music of any kind never exits for its own sake as imagined previously by those autonomic aestheticians. Rather, music, or spelt in its plural and capital form as "MUSICS" preferred by some ethnomusicologists and educators, reflects many aspects in the civilization created by mankind. It is unthinkable for music to be generated from vacuum.

\subsection{The Authors' Views to Support the Rationale}

Based on these beliefs, we put forward our reasoning in the case of music for the purpose to foster students' outlook of a whole world:

1. Music of any kind is created by and for the people through their labor and life in specific times and spaces.

2. Music, therefore, may function as a window through which people explore the universe, society, and human self.

3. Music, as far as a holistic education is concerned, is essentially an ideal starting point to implement the interdisciplinary approach when it is neatly applied to areas of language arts, geography, history, and others.

Why? The answer is that music connects. Music goes together with language in lyrics of songs; it bears geographical and historical "footprints" because it originates spatially and temporally, from places around the world and in eras across times; in countless human endeavors music is ubiquitous. And the key for music to function fully in educating the youth to develop and finally possess, in the epistemologically significant sense, an outlook of the universally connected world lies in the teacher's mind. How to think in and out of music is critical for the teacher. Whether is he sensitive enough to discern potential connections between music and the world beyond music? If yes, to what extent is he capable to gain a meaningful insight into the values hidden beneath them to inspire students' own minds? In short, the teacher must be a thinker with views broader than a musician performing musical notes merely. An illustration is presented hereafter.

\section{Attributes Crossly Shared in Related Disciplines}

\subsection{Common Attributes Across Related Disciplines}

To design an interdisciplinary learning approach that starts from music and goes beyond music, one should understand that this approach is not to make music learning as a tool to crutch learning of other disciplines, but to learn in music first while making it become a window through which students explore into the whole universe far beyond routine experiences, search for charming networks in the society or a community around them, and reflect on themselves in daily life. Of all these potentials, the key is to focus on something which bears educating values more than letting students acquire mere knowledge in one discipline. For this purpose, the designer should first examine the common attributes explicitly or implicitly embodied in the related disciplines or threading through them. To reiterate the point, we must remind not to stay on a surface work easily done without scrutiny, but to dig as far and deep as possible into the internal relations and common points among different disciplines and think of strategies leading students to discover the hidden connections underneath the surface of different phenomena seemingly irrelevant or isolated. It seems a daunting task, but the teacher will soon find clues between music and other phenomena. For an example, we may start from a "common sense": the seasons and the Sun-Earth relation. In talking of this "common sense" in daily experience, one would take it for granted because the phenomenon is too familiar for us to think further. However, if one speculates deeper in music together with many other substances and concepts in life, he will soon become aware of the fact that it possesses a common attribute reflecting a law that dominates the world -- PERIODICITY. It dominates the orbit of the Earth around the Sun; it is right within us dominating our blood and breath for every second of life; it denotes a critical conception perpetually circulating in all the beings, no matter it is organic or not. In short, it is a dominating law of the Nature and human beings.

In what way does it connect to music? Simple! One cannot start music leaning without counting the meters or popularly called pulses----One two, one two; or one, two, three, four. The meters or pulses we call in music are an initial point for music learning. And this very simple doing in music connects a glorious law of universe. The duple and quadruple meters in music verify rightly that music is a microcosm of the Universe in their common attribute--- periodicity. This is just one example of the many potentials that music connects to other aspects of the world.

Then, what does it matter with music teaching and learning? What is the significance for students to acquire an understanding of such an attribute? It does matter; and it makes a difference. It determines young generations in the future who are creative people or memory machines of books. The former thinks from a wide view covering the whole world and what the latter can do is limited within a narrow category: near-sighted, isolated and 
nothing more than the knowledge memorized superficially for a satisfactory score on the test and forgot afterwards.

\subsection{A Common-Attribute-Based Theme and Connections}

To conceive a theme which embodies a common attribute from music to other areas of learning, the teacher might be at a loss at first. Where and how can I find a theme which possesses a common attribute connecting to other disciplines and is meaningful to expand the students' thinking in wider perspectives? The teacher is most likely to ask himself such a question. To help the designer to start, we propose a "down to earth" way of thinking for such a theme.

Let's think of music this way. Any kind of music comes out and exists in a particular place and time. Consider folk songs in China. Some songs are from the North and some from the South. Geographically, these two are different. The North is mountainous, and the South is of wide plains. This rough description is not very accurate but for the present purpose, it may be good enough for a general saying.

Let's think further about folk songs. Songs are sung with a lyric which brings us to a key point. It is widely known that Mandarin is spoken by all Chinese. But there are about ten categories of topolects or dialects which all belong to Chinese language. People in different parts of the country speak varieties of local Chinese with the same Chinese characters. If we examine these ten categories of dialects closely and divide them further into more narrowly geographic conditions, we cannot count the numbers. Many! Of course, it is not our point to count how many. The point is what kind of common attribute that folk songs connect. This down to earth method of thinking results in a series of answers.

The first is that the language of Chinese is spoken by all Chinses generally while the dialects are spoken by people in different localities specifically. Some linguists out of China may know that there are four tones or pitch variations in Chinese characters including Mandarin and most dialects. They are spoken as level tone (阴平), rising tone (阳平), falling-rising tone (上声), and falling tone (去声). We explain this by a comparison on one Chinese character spoken in Mandarin and local dialects. That is, a Chinese character with one and the same meaning might be spoken in different tones. For instance, the Chinese “妈” for the English word "mom” is pronounced as "MA". It is pronounced in Mandarin as level tone, whereas it is pronounced as rising tone by people in some parts of Henan province, and in falling tone by people in certain regions of Gansu province. This is amusing though a little confusing to many foreigners. However, it is right from this phonetic phenomenon that we discern an important clue which can be used as a common-attribute-based theme to create a perfect design for an interdisciplinary learning. According to Chinese music theories, the varieties of tones in different regions in China have found their ways into the folk songs created by generations of people. To make things simpler, we return to the example of the Chinese character “妈” pronounced as "MA". When people speak it in the rising tone, they most likely sing it along the rising tunes or the ascending melody, while those who speak it in the falling tone incline to sing it from high note(s) to low note(s), along the descending direction melodically. We continue with more detailed explanations below.

Observing the lyrics sung in Chinese folk songs, one may find a general law, in the sense of composing as well as singing, that the melodic move or the contour of tunes of Chinese folk songs follows the directions of tones' move spoken in varieties of Chinese dialects. This law has been recognized and accepted by many Chinese musicians and scholars [9, 10]. It is named in Chinse as “以字行腔” which might be literally expressed as "based on characters to process the tunes". Here "characters" mean the Chinese words including dialects while "process" refers to both composing and singing or rendering musically. In other words, it means that the melody goes up and down along the moving directions of spoken Chinese words. Reversely, the ups and downs of the tones spoken influence the creating and singing folk songs in regard of melodic directions.

We might borrow a terminology - isomorphism - from psychology and aesthetics to fix the meaning of the law discussed here. It refers to the similarity between the utterances of language and singing of folk songs by Chinese. We use this terminology to reiterate our point in finding a theme which possesses a common attribute between music and the related phenomena.

For the example below, this common attribute could be described as "Isomorphic Move between Dialect Tones and Melodic Tunes” or simply“声腔同形”in Chinese while the theme could be named as "Folk Songs Connect to Conditions of People." They become the starting point to connect more aspects.

Let's think deeper and wider. The different dialects connect geographically different regions. And the different geographic regions connect different ways of laboring and different living styles of people. In considering how people in different regions are influenced by these elements, Feiqun Shu, the author of this article, depicts elsewhere that in the Northwest of China,

The distance between villages and the sloping farms of the region is so remote that farmers and their families must shout using high pitches and loud voices for effective communication, such as calling people for meals. These circumstances make the local language or dialect sound rough and rude. The characteristics of the language find their way into the local singing style, creating long rhythms and high-pitched tunes as well as strong emotional expression.

The Southern folk songs and singing style are quite different from that of the North:

The low, flat plains of these regions, which are crisscrossed by rivers and lakes, have fed hundreds of generations of people with "fish and rice." This Chinese metaphor refers to a life that is abundant, with nature supplying more than is needed, allowing people to afford better schooling and the study of the arts. In addition to folk songs popularly sung by farmers and fishermen, literature, poems, visual arts, and songs with texts reflecting a high-class lifestyle and ideal existence have emerged in upper-class intellectual circles. This has, in turn, influenced ordinary people's taste in 
singing and other performing arts. Elegance, lightness, and subtleness representing scholastic-poetic ideals as well as delicacy of craftsmanship are the style of singing preferred and practiced in the south of China [11].

The comparative descriptions provide hints for connecting styles of music with people's conditions, extending even further to mental and emotional dispositions inside the people influenced by these conditions viewed from historical, geographical and other dimensions. These relations can be outlined as a model in figure 1.

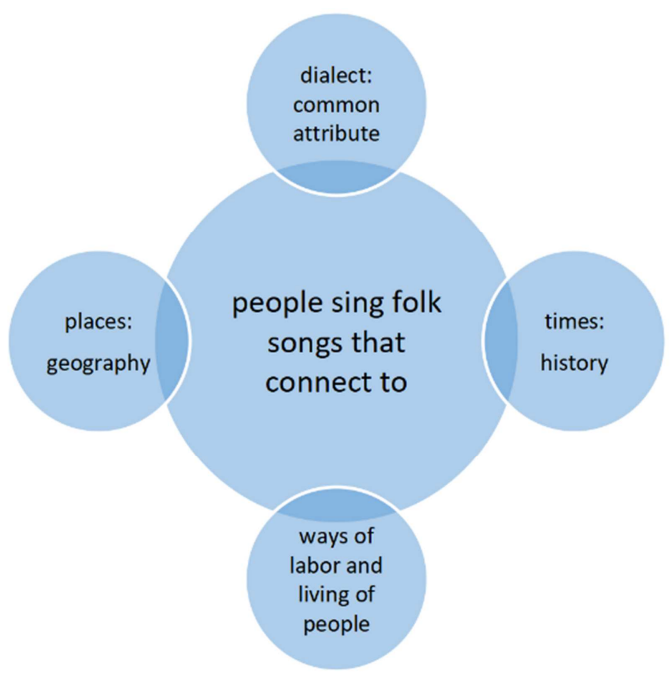

Figure 1. A common attribute based on isomorphic move between dialect tones and melodic tunes —_Folk songs connect to conditions of people.

\section{An Exemplary Project for Interdisciplinary Learning}

\subsection{Concerns for a Student - Centered Project}

There is a key principle for the teacher to design a project for interdisciplinary learning. He must ask himself who should be actively standing and working at the center of the project: the teacher or the students? It is not smart for the teacher to directly tell students how and where the project goes and why. The right way is for the students to become the agent, searching, doing, thinking actively throughout the whole process while the teacher should be acting a hidden role to observe, support, question, and lead the students on the way for self-exploring.

As stated above, the first concern is to establish a theme possessing a common attribute across different areas of learning. For the example below, this theme is based on the common attribute, that is the isomorphic move between dialect tones and melodic tunes. Then, the teacher should look for potential connections between folk songs and many other conditions of people as illustrated in figure 1, expanding to the geo-historical context in explanations of traditional ways of labor and life. This expanding step will enlarge the students' vision to wider and deeper perspectives of the world.

The second is to make a judgement about the students' readiness for the project. Whether are the students able to deal with the project based on their previous experiences? Is the project too hard or too easy to make a sense for them? Balance must be made by the teacher to provide them something that is appealing and challenging enough to arise their curiosity for probing further. If the project looks too naïve, the students might not be interested. Anyway, the students' experiences in music and related areas must be in accordance with the tasks content and learning materials.

The third is to reflect further on the significance of the common attribute. This is a core expression of the connotation of traditional Chinese music, especially in folk songs which bear local dialects from spoken Chinese characters to melody sung by local people. Defined as an unfixed-tone or unfixed -pitch system by some western musicologists, it is perhaps the most salient attribute inherently immersed in folk songs in China and might be identified as one of the cultural essences of traditional Chinese music, substantially different from the fixed-pitch concept in western music. Holding with this belief, the teacher has come to a true understanding why it is chosen for the project and where he should lead the students to explore along this line of thoughts.

The fourth is to conceptualize a logically convincing line as a rationale for the project: starting from music and going beyond music to related areas of learning so that this interdisciplinary learning inevitably occurs and threads all the related areas without external imposition. We may consider a sequence covering main elements for a whole process of the interdisciplinary learning:

The melodic tunes in Chinese folk songs are inseparable from the speaking tones in dialects in different localities in China. And this tunes-tones relationship between music and language can be technologically tested by a phonetic analyzing tool like PRAAT [12] or SFS/WASP (Speech Filling System of the WASP Brand) [13] which facilitates the students to develop an experimental ability blending music, language, science, and technology.

Folk songs and dialects originate from the labor and life of people in different regions with relevant conditions, reflecting the folk customs in different localities. Here are potentials for the students to experience subtle influential effects on their love of hometown and people by knowing more of the styles of people's labor and daily life. Here are also potentials for the students to experience certain values based implicitly on an aesthetic education ideal for educating through culture, which is beneficial for students to form positive values and artistic views. The intrinsic links running through music, language, science and technology, geography, history, humanities, and morality constitute the main points of interdisciplinary activities for educating young people in an interdisciplinary manner.

To summarize the above points, the teachers may refer to the model illustrated in figure 1.

Like the design of a lesson plan, the teacher's fifth concern is to list important steps running through the project to lead the students' explorations.

Essential questions [14]: How are the characteristics and features of folk songs related to dialects, regions, folk customs, and people's life? The teacher should presuppose specific questions further that lead the students to go through a progress step by step and guide them to find and solve 
problems in various stages of this interdisciplinary learning project, from the near to the far, from the shallow to the deep, from the external to the internal, encouraging them to explore the life phenomena and cultural connotations that are connected between different disciplines.

The educational values and purposes: The students' interdisciplinary explorations into dialect tones are in comparison with tunes of folk songs, relating to geo-historical elements such as people's labor and living customs. These activities have comprehensive educational values when the students face the questions and solve the problems, explore independently with tools and methods, follow the theme in related disciplines, and develop the ability to draw inferences and conclusions. Additionally, this student-centered project enables them to understand and establish a critical view that the folk songs are created by the people; they are generated from people's labor and life, and reflect various features embodied in traditional culture.

Music content and key points for learning: Two categories of folk songs should be chosen as music content to start learning. One should be of the North and the other of the South in China. The purpose, as well as the key points, to choose the folk songs in these two categories aims at a task for the students to compare the differences between them while recognizing the common attribute as stated earlier. Based on their singing and listening experience, the students are expected to perceive and discern salient features of the modal or scale styles, the relations of moving directions between the tones spoken in the dialects and the tunes sung in the songs. And the key point is to compare differences of characteristics between the North and the South. The students might be able to discover that different music elements, such as the narrow or wide range of songs, modes or scales, melodic intervals and progressing styles, the timbre and articulation of singing, etc., connect to many characteristics of people living with different conditions and relate to geo-historical extensions.

Tools and methods: The tones spoken and tunes sung in the songs can be measured and drawn as curve lines using the acoustic software PRAAT or SFS/WASP. The distribution of Chinese dialect regions can be searched on the web, for instance, a Geomorphology Mind Map might be helpful. The students should focus on the relations between geography and historical stories pertaining to people's life, labor, and customs, search the typical features of mountainous areas in the North and low flat towns in the South, check any links existing between these elements, observe various appearances of rivers, mountains and plains, and finally show the evidence to illustrate the connections and implications.

Provisions: The teacher should provide sheet music of folk songs with comparative purpose, recorded in video format, and lyrics of folk songs pronounced by genuine local voices. Tools such as PRAAT or SFS/WASP might be found on web for free use to measure and draw the curve lines of voices of lyrics and tunes of melody. Other data searching facilities must be ready for the students.

\subsection{A Guideline for Students}

The steps below are suggested to the students but are not necessarily followed strictly.

The students sing the folk songs and focus on the essentials between different origins of the folk songs. With singing experience of folk songs, they might be asked about differences and characteristics of the two tyles of folk songs, focusing on the salient features in terms of mode or scale, melodic move, pitch range, timbre, and rendering of singing. Given necessary guides by the teacher, the students are expected to summarize the differences between the two types of folk songs. Note: The students' response should be closely geared to essential questions and the common attribute to avoid deviating from the theme without educative purpose in the progress of activities.

The students explore dialects and conduct experiments. They choose an acoustic tool to test tones of dialects and tunes of melody, drawing curve lines and comparing them. Given the evidence from the test, they verify and answer the questions: What are the similarities and differences between the musical characteristics of the two types of folk songs and the two dialects in tone-tune relations, timbres, pitch ranges, and volumes, etc.? Note: The students are guided to observe the salient features of musical elements.

The students observe folk customs and find out connections. Where do the two types of folk songs come from in China? Could you find out the places where these folk songs originate on the map of China? The students search for the places and discuss the regional features of the two types. Note: The students are guided to connect music to labor and living conditions of people based on the previous learning experiences and knowledge in literature, geography, and history. In-depth study on people's traditional labor production and living customs in different geographical environments should become the focus to find out the connections between musical elements and people's ways of labor and living with specific conditions. It is occasionally necessary that the teacher observes and provides guidance, but the conclusions from the study should be made by the students themselves.

The students discuss, write, present, and refine their work in groups to exchange experiences in the process of exploration and prepare reports presenting the study results and insights gained in the process. They may also use the narrative method to report the genuine process and experience of inquiry. Note: The teacher may assist students in planning and laying-out, leading them to reflect on the ideas, significance, purpose, methods, processes, results, and discussions of research. Finally, it is important for the students to make music musically. They are expected to refine their rendering of songs with proper styles based on the deep experience and gain lasting impressions of folk songs.

A meaningful assessment is set for the students' achievement. Key points for the assessment should be established which focus on the development of the students and they are supposed to grasp the common attribute with open oriented responses and opinions. The students' exploration might cover the following points: summarizing the differences and similarities between the two folk songs based on the PRAAT curve lines of two folk songs, showing the regional characteristics, ways of people's labor and customs of 
life in relation with the places where the songs originated. Note: The quality of singing should not be neglected and the students should demonstrate improved musical rendering.

Finally, it is emphasized that creative and artistic thinking shown by the students should be respected during the exploration process. The students should be encouraged to think originally and independently by presenting various opinions and considerations. Ideally, they might be able to transfer what they gain previously to the new interdisciplinary situations as elaborated in table 1 . It is on this point that the true purpose for the interdisciplinary learning is realized. However, it takes time and patience must be held.

\subsection{Suggestions for Teachers}

The teachers are supposed to lead the students actively participating the whole process themselves rather than passively informed by the teachers. The students should make progress through their own decision making and working strategies. On the basis of this belief, suggestions are provided below for the teachers.

Suggestion 1: Focusing on the students' growth and making the project educatively meaningful. With the essential questions in mind, the students start from exploring the secret of tones spoken and tunes sung in the lyrics of the folk songs. While singing and perceiving the songs, the students think of the connection between the two, comparing the isomorphism of tones-tunes relations concerning the ups and downs moving directions. Then they go further to the geographic regions where the folk songs originated and explore the ways of people's labor and life possibly influenced by these conditions. Historical contexts might be included for them to better understand reasons why people in different regions have developed their distinct dialects, folk song tunes, lifestyles, and even mental and emotional dispositions. Most importantly, the students are expected to abstract from all these phenomena a conclusion that music connects. In a word, this project should become educatively meaningful, and contribute more than a routine work for the students to go through without gaining an insight.

Suggestion 2: Speculating profoundly but operating feasibly. It is true that a project as this kind focuses on the in-depth development of the students. Thoughtful appreciation is the core. When laying out the activities for the students, however, the teacher should consider the students' previous experience and development characteristics with caution not to exceed what the students can do and understand truly. A smart teacher should make things simple and suitable for the students. The purpose might be sophisticated but the task should be obvious; the reason might be profound but the method should be plain; the questions might be philosophically implicit but the way to present the questions should be straight forward; the planning might be systematic but the steps, tools and strategies suggested to the students should be easily workable. With these considerations in mind, the teacher might enable the students to dwell on the essential questions sequentially. One more word must be given to remind the teacher that the overall design and specific steps predicted by the teacher are not strict rules. The students are the master for the final say. It is indeed a big theme aiming to foster the students' outlook of universally connected world, but ways to lead the students to arrive at this aim vary. No matter how many details the teachers make, flexibilities should be allowed and encouraged.

Suggestion 3: Believing in the students while providing support and assistance. The project is student-centered; it is an upmost principle for the teachers, especially for those who incline to underestimate the students' potentials in discovery. The teacher should remember that a true understanding comes from hands-on working. Being informed is occasionally necessary but it should not be heavily imposed for student-centered learning. On the contrary, the teacher should motivate the students to search and research while a hint, a metaphor, and a clue might be suggested to them at a critical moment. Of course, the teacher must predict where and when the students will meet frustrations beyond their ability to sort out a solution. The alternatives of methods and sufficient resources should be prepared to give them assistance when necessary. For example, if a tool like PRAAT is not available, the students should be encouraged to hand-draw the curve lines of pitch direction by listening to find out similar characteristics between folk songs and dialect tones. If they are not ready for relevant geographical and historical knowledge involved, the students may use computers or mobile phones to search for the related resources.

Suggestion 4: Encouraging multiple opinions while proposing positive values: It is predictable that the students come to different opinions in their activities. The teacher should encourage them and let them recognize different angles to view things. At the same time the teacher may guide the students to establish positive values. For example, one should respect various styles of folk songs and dialects in different regions, the vigorous sounds of the North in comparison with the subtlety of the South. The key point for the students is not to stay at the level of sound perception but to dwell on the deep reasons why people living in different environments express music differently in relation to distinct conditions around them - geo-historically with all the aspects in life.

\section{Conclusion}

During many years of practicing interdisciplinary learning approach, music has been used to assist learning for other areas or subjects. Unsuccessful trials such as using music to enhance intelligence test score or so called "Mozart Effect" belong to this kind [15]. Initially, such practices might come from a good will to advocate music as a basic course of study and to promote the values for music learning in school. They have brought, however, more negative results than positive. The point of view in this article differs. The title of the article makes it clear that the aim for the interdisciplinary learning is to foster students' outlook of universally connected world. This is an ultimate ideal that must go through various levels as illustrated in table 1. As music teachers, we trust that music never exists for its own sake. Music connects! Evidence from research of archeology, history, anthropology, sociology, 
philosophy, psychology, and many other sciences support this viewpoint [16]. We believe that the educative values of music are far from fully recognized and these values should be cherished and fully used in educating the young generation, assisting them to develop ways of thinking with an interdisciplinary mind, free of constraints and limitations. Many educators in the past were in favor of fostering thinkers because they changed the world with their powers of discovery and a brave mind to imagine unboundedly, crossing through the imposed boundaries of "subjects" or "disciplines". Once the school subjects are learned in an interdisciplinary manner and the students think with the ideal ways advocated by Pythagoras and Confucius, they will be benefited tremendously for their development of wisdom. It is based on this ideal that we postulate the topic of "Starting from Music and Beyond." We hope that the students may observe the world through music as a window and gain rich meaningful insights while acquiring beautiful performing skills and thoughtful musical understanding.

To realize this profound ideal for music to function more than just an art form leading students to broaden their world outlooks universally, follow-up studies should be conducted and the key to deepen this interdisciplinary approach is to further explore various potentials music connects to the world. The task urges teachers to think beyond one subject or discipline and reflect on connections that make the world as an integrated whole. Opportunities are abounded. For instance, a teacher may teach music philosophically, sociologically, historically, and even scientifically. And the reverse is true. A student may gain an insight for the law of "unity of opposites" from philosophical speculation while hearing vividly the musical law of "unity and variety" which is ubiquitous in music presented melodically, rhythmically, harmonically, and formally.

\section{Disclosure Statement}

The authors declare no conflicts of interest.

\section{References}

[1] Confucius (2008). The Analects. trans. D. C. Lau. Zhong Hua Book Company, 107.

[2] Applebee, A. N., Adler, M., \& Flihan, S. (2007). Interdisciplinary curricula in middle and high school classrooms: Case studies of approaches to curriculum and instruction. American Educational Research Journal, 44 (4): 1002-1039. DOI: 10.3102/0002831207308219.

[3] Bruner, J. (1967). The process of education. Harvard University Press, 5.

[4] Abeles H., Hoffer, C. \& Klotman R. (1995). Foundations of music education, 2nd ed., Schirmer Books, 4.

[5] Elliott, D., \& Silverman, M. (2015). Music matters: A philosophy of music education, 2nd ed., Oxford University Press, 54-105.
[6] Shu, Feiqun (2018). The social and ethical pursuit of the praxual philosophy of music education. China Music $\begin{array}{lllll}\text { Education, } 2018 & \text { (7): } & 4-9 . & \text { DOI: } & \text { CNKI: }\end{array}$ ZYJA.0.2018-07-002.

[7] Shu, Feiqun (2019). A study on an oriental trend in the western philosophy of music education. Chinese Music, 2019 (1): 171-175. DOI: 10.13812/j.cnki.cn11-1379/j.2019.01.022.

[8] Elliott, D., \& Silverman, M. (2015). Music matters: A philosophy of music education, 2nd ed., Oxford University Press, 87.

[9] Shen, Qia (2019). A theory of tunes. Shanghai Music Publishing House, 3.

[10] Du, Yaxiong (2019). Ten basic concepts of Chinese music fundamentals. Chinese Music, 2019 (1): 18.

[11] Whitener, J. \& Shu, Feiqun (2018). An introduction to the music of China. Music Educators Journal, Vol. 105 (Dec.): 18-27. DOI: $10.1177 / 0027432118811587$.

[12] Baidu Entry. PRAAT: Doing phonetics by computer. https://baike.baidu.com/item/praat/7852897?fr=aladdin

[13] SFS/WASP. SFS/WASP help file. https://www.phon.ucl.ac.uk/resource/sfs/wasp/wasp.htm

[14] McTighe, J., \& Wiggins, G. (2012). Essential questions: Opening doors to students understanding. ASCD.

[15] Shaw, G. L. (2000). Keeping Mozart in Mind. Academic Press.

[16] Hodges, D., \& Sebald, D. (2011). Music in human experience: An introduction to music psychology. Routledge.

\section{Biography}

Feiqun Shu. A Chinese doctoral student at the Faculty of Music, BangkokThonburi University in Bangkok, Thailand. Her research interests include philosophy, psychology, neuroscience, curriculum and teaching in music education. She has published some twenty research articles in Music Educators Journal by National Association for Music Education in U.S.A., and journals in China such as Chinese Music, China Music Education, Yearbook of Music Education in China, Teachers Journal of China, and Xinghai Conservatory of Music Journal. She participated research projects funded by China National Social Science Foundation and Da Cheng Sinology Foundation of Hong Kong, China.

Panya Roongruang. An internationally renowned scholar and musician, Roongruang is the $\mathrm{PhD}$ program supervisor in ethnomusicology and music education, and the Dean of Faculty of Music, BangkokThonburi University in Bangkok, Thailand. He received his $\mathrm{PhD}$ at Kent State University, U.S.A. in 1999, and published numerously for New Grove's Dictionary of Music and Musicians, Garland Encyclopaedia of World Music, and the monograph of Thai classical music and its movement from oral to written transmission 1930-1942: Historical context, method, and legacy of the Thai music manuscript project, as well as the series of Collected Works of the Thai Classical Repertoire. 